\title{
Re-placing Performance in 'Art': the case of Françoise Sullivan
}

\author{
Karen Stanworth
}

\section{Re-situer la performance dans l'art: Le cas de Françoise Sullivan}

Cet essai examine l'oeuvre de Françoise Sullivan à partir de la poétique de l'improvisation des Automatistes. Par son mélange des formes poétiques et visuelles avec la danse, cette pratique transgresse les normes de l'Art et se fait appeller de l'artisanat par la critique. Depuis 1970, cependant, la pratique de Sullivan s'oriente sur une interrogation de la représentation et une exploration "consciente" des relations du pouvoir entre les hommes et les femmes. Alors, il n'y a pas de continuitié dans l'oeuvre de Sullivan, saufqu'elle refuse toujours de s'aligner aux normes consacrées.

Performance art exists ambiguously in the space between 'high art' and those apparently more populist forms of public expression such as dance, theatre and music. When an artist, such as Françoise Sullivan, produces work within and across both the popular and so-called 'high art' forms, critics prove unable to resolve the perceived contradiction between craft and art. As a consequence, Sullivan's performance pieces of the 1970s have been critically subsumed into her prior art practice. Despite the evidence of site specific work, of pieces which articulate a particular history, and of shifting realms of concern, critics have continued to view Sullivan's performance pieces of the 1970s and her paintings of the 1980s through the lens of Automatisme, virtually precluding any other reading of Sullivan's work. This paper attempts to address this critical lacuna by retrieving the specificity of her work after 1970, and by examining whether that practice is continuous with the Automatiste stance of the 1940s.

On August 9, 1948 in Montreal, Paul-Emil Borduas and fifteen Quebecois artists, dancers and poets signed and published a manifesto, The Refus global, which profoundly rocked the socio-cultural foundations of Quebec. The artists involved became known as the 
Automatistes due to their emphasis on the necessity for 'automatic' or spontaneous expression. The spontaneous, whether literary or visual, was proposed as a means of counter-acting the rules of production implicit in art and society. The Automatiste manifesto articulated a refusal to accept any personal, social or aesthetic confinement. The lead manifesto declaimed all forms of "intention, the two-edged, perilous sword of reason" and proclaimed the necessity of magic and "objective mysteries." 1

The manifesto has been both damned and praised for singlehandedly undermining the status quo in Quebec. The motivations for its production in the summer of 1948 were tied to various personal and professional quarrels, post-war dissatisfaction, local politics, etc. While it has been generally acknowledged that the manifesto was the product of its time and place, and therefore served as a prelude to the Quiet Revolution in Quebec in the 1960s, it has ironically been preserved primarily as an aesthetic and philosophical movement by Canadian art historians. In particular, Françoise Sullivan's contribution to the manifesto, "La Danse et l'espoir," has been interpreted as being somehow autonomous from the socio-political aims of the Automatistes. Disconnected from history, the artist becomes the aesthetic pawn of her own writing. Critics seek the writer and dancer of 1948 in all her subsequent production, disregarding the relations between choice of medium, subject/object meanings, socio-cultural context and personal history.

The desire on the part of the Automatistes to overthrow the entrenched relations of power, whether artistic or political, secular or religious, apparently was informed by a Jungian rhetoric. Borduas' lead text incorporated references to the collective unconscious and psychic energies of the Quebecois - references which had appeared previously in Sullivan's public reading of "La Danse et L'Espoir" ["Dance and Hope"] six months prior to the publication of the manifesto. ${ }^{2}$ She, in turn, likely developed her notions of how the collective unconscious might be expressed in visual form by drawing on the anthropologically-informed dance theory of Franciska Boas in New York and on discussions with her childhood friend and co-signatory of the Refus Global, the poet and psychologist-in-training, Bruno Cormier. $^{3}$

Sullivan proposed that the modern dancer was capable of discovering a common culture which had been shared by everyone at some 
undefined point in the past. The body was seen as the storehouse of cosmic energy which was released through automatiste dance. The dancer could go "beyond the individual towards the universal." ${ }^{4}$ This "universal" or the collective unconscious is expressed through symbolic themes underlying the automatic dance performance. For the Jungian, the symbol is the essence of the psychic energy and may be archetypal, that is, it may be derived from mythic themes whose symbolism illustrates universal human history, or, the symbol may have personal significance, revealing the unconscious. In the performances in which Sullivan danced alone, as in Danse dans la neige (1948), she attempted to release her individual psychic energy through movement - movement, which she proposed would symbolize the universal or collective psyche. ${ }^{5}$ She also sought to recreate archetypal symbols, as is exemplified by her reference to the 'Shadow,' defined by Jung as "our other self." The archetypal symbol of the Shadow underlies her performance of Dualité where two dancers, Sullivan and Jeanne Renaud, one in black, one in white, enacted themes of opposition and attraction.

While Sullivan's dance and choreography of the 1940s was explicitly Jungian in its automatiste enactment of symbolic, 'universal' elements, I question the authority of this interpretation in her subsequent production. In particular, Sullivan's return to the 'high art' medium of painting in the 1980s, has reinforced the tendency to read the predominantly performance and site-specific work of the 1970s as part of an aesthetic, ahistorical progression from Automatiste dance to contemporary painting. This framing of Sullivan's performance pieces by 'high art' reduces them to contributory elements rather than acknowledging their disruptive challenge to the aesthetic centre.

The critical placement of the artist's contemporary work in tangency to her Automatiste oeuvre is exemplified by a recent analysis of Sullivan's painting, in which the critic characterized Bezvare! Beware! His flashing eyes, his floating hair (1983) as exemplary of Sullivan's "desire for tangency with the universe." ${ }^{6}$ The painting depicts a figure with arms outstretched and legs apart with most of the body weight balanced on one leg. The figure appears to be female. She is framed by a rectangle which is inscribed in a circle, but the rectangle breaks through the confines of the circle at the base. This image is described as "a metaphor of the universe and of pictorial representation, since the artist has made a summary of her own body by placing 
herself on the canvas... [This depiction] evokes the excessiveness of the body that merges with the universe." 7 The writer has shifted from describing a symbolic interpretation which seeks to rediscover ancient truths (i.e. through a unifying symbol) to describing a metaphor which defines something other than what is portrayed. However, I would suggest that if the represented body is indeed a symbol of the artist as the personification of the body merging with the universe, then it cannot also be a metaphor unless the intention is to challenge the symbolic representation through an allegorical stance. That is, the artist may be consciously manipulating symbology (here, the symbol is of man at the centre of his universe) as part of a disjunctive symbol, more correctly called metaphor, (woman de-centred in her universe). This grammatical rhetoric may be further complicated by the introduction of other narrative and emblematic imagery, such as the painting brush and the scorpion. If the scorpion, as a symbol of astrological identification, is a universally understood sign (the sign of November, the end of the year, thus the end of a cycle), that reading is being challenged by the juxtaposition of the dark masking of the face. Is the masked face a further rebuttal of cosmic harmony? Or does it reinforce a negative interpretation of the presented cosmology? When formal considerations are added to the whole set of represented relations, such as the ephemeral drawing of the body compared to the vehemence of the swirls of paint in her immediate space, then the reading of the image is far more complicated than is implied by the idea that "the excessiveness of this body merges with the universe." Rather than merging, it would seem that displacement or uncertainty of position is the artist's concern in Beware, beware,... The irony is further underlined by Sullivan's use of Coleridge's poem as a source for her title since Coleridges's concept of the unity of the symbol to its referent is so obviously being queried by the artist.

Rather than following the Surrealist paradigm "to explore the subconscious and to expand the boundaries of memory as knowledge," Sullivan appears to be questioning the very possibility of that inwardly directed approach. ${ }^{8}$ It may be that such a challenge would be the inevitable result of her optimistic desire to "unite objective space and dream space" while at the same time insisting that "art can only flourish if it grows from problems which concern the age." ${ }^{9}$ How can the transcendent transcend the temporal, if it must be sited in it? Sullivan's automatiste desire for cosmic consciousness may have 
shifted to a desire to attain consciousness of temporal realities over archetypal escapism, I would like to suggest that the change from modern to anti-modern, or from symbolic unity to rhetorical stance, is located in her internal struggle with the so-called death of art. ${ }^{10}$

After reading Joseph Kosuth's The Philosophy of Art (1969) in which he announced that the world was overstocked with art which was no longer necessary or valid, Sullivan was prompted to face her growing discontent for abstraction which had dominated art in North America for two decades. She had been following this pattern in her minimalist sculptures such as Aeris Ludus (1967) which strives to attain a harmonious whole executed with a few basic shapes unified in orange paint. In an interview in 1972, she declared:

"Like many other artists, I was distraught. I had a great love, at the depths of my soul, for art, but I was uneasy to even pronounce the word. The artist consecrates her life to do a job which is nearly no longer plausible. Our world is saturated with art objects. So what do we do now? I do not think today that artists are happy because of this gap between what the artist is doing [minimal art] and what the artist wants to do ...." [1973] ${ }^{11}$

In addition to the aesthetic and philosophical impact of Kosuth, it is necessary to note the ramification of Sullivan's lived experience for her art production in the 1970s. Her biographies, whether copious or brief, all mention her marriage to Paterson Ewen and the birth of her four sons through the 1950s. This personal data is relevant since this period of alienation from art during the years of 1968-70 was also a time of private estrangement as she was in the process of separation from Paterson Ewen (also undergoing a personal and artistic period of reassessment). This is also a period of extreme political and social upheaval in Quebec which witnessed the student riots in the colleges and six universities in the province. Local education was being wrestled from the control of the Roman Catholic Church. The Parti Quebecois was founded. By 1970, the F.L.Q. crisis with the kidnapping of Cross and Laporte and the enactment of the War Measures Act exemplified the inability of the Quebecois to realize harmony within the federal system. It is no surprise that this is the time for questioning the pursuit of the unifying potential of art. Sullivan's historic association with the Automatistes had set a personal precedent for her in that she was not afraid to challenge the status quo. By 1970, the status quo 
presented by formalism was not satisfying Sullivan's need to answer Kosuth's challenge regarding the death of art. In 1973, in reference to her installation work and that of other contemporary artists, she stated "we are not interested in problems of form and colour any more. We are working at another level." ${ }^{12}$ The need for authenticity in representation was pressing. All of Sullivan's subsequent work presents a continuing challenge to the nature of representation, and of the presentation of the subject. Rather than seeking continuity in Sullivan's work, it may be more constructive to acknowledge change and to assess the work of the past two decades within an anti-modern position. I would like to suggest that this recent practice is characterized by a shift from symbolic unity to a fractured discourse of the other realized within a rhetorical stance which uses symbol and allegory to challenge representation and its reception by the artist and the viewer.

The paradigmatic shift (not a complete break) which I place at the inception of Sullivan's self-conscious, anti-modernist practice is the change from internal coherence in art to external reference, usually ambiguous and always contextualized. The breakdown of the modernist conception of art as a 'hard-won unity' of surface and spatial tensions to a reconstruction of referential meaning in art (whether feminist, gay, social, ecological, etc.) is seen in the move from minimalist essentialism to a plethora of references in Sullivan's post-1970 work.

Her anti-modernist stance is exemplified in the 1970 s by her promenades, such as Rencontre avec un Apollon archaïque (1974). I would like to suggest that her performance pieces such as the 'promenades' are very much a part of her choreographic strategies. It is in these works that the dancer who wrote "La Dance et l'espoir" abandons a vision of harmony in order to begin a re-assessment of what art has to offer her. Her 'encounter with Apollo' is explicitly referential. She takes her 'encounter' out of doors. It does not exist except as a photographic record. The artist/dancer moves in a choreographed path through Montreal's East End refineries searching through the detritus of the industrial age for a sign of classical art. What does the A pollo signify? Or should the question be how much does it signify? The possibilities range from a personal search for traditional values in artistic practice, to a feminist confrontation of the perfect male presence, to a postmodern questioning of the value of representation itself (symbolized 
by Apollo) in a world so cluttered that Apollo can be reduced to a simulacrum posted randomly amongst refineries.

Once again, an artist/critic classified Sullivan's production, now the promenades, as consistent with Automatisme. In the catalogue from the retrospective exhibition of Sullivan's oeuvre, it was stated that the motive for her "submission" to antiquity in her Rencontre d'un Apollon parmi les raffineries de petrole becomes "clear and coherent" when one recalls that she believed in the "rediscovery of the truths already familiar to the ancient primitives ..." (1948). ${ }^{13}$ However, I would suggest that the parallelism between the use of A pollo and the search for ancient primitive truths is not as "clear" as is implied because, as a sign, the A pollo elicits numerous readings and it cannot be assumed to signify a universal archetype.

This questioning of the authenticity of the symbol, its reception and the consequent validity of representation appears to inform all the post-1970 work. It is essential to consider Sullivan's performance pieces in light of her conscious choreography of space and time relations. It is not coincidental that her performance pieces are awkward to categorize as dance or installation.

As a text, Hiérophanie, a performance/installation/dance piece of 1979, partially assists in the examination of the shift in Sullivan's position relative to aesthetic ideologies. Hiérophanie was Sullivan's first major choreography since the 1950s. It was characterized by the 'dirviches-tourneurs' often present in her earlier pieces (notably in the pieces in which she danced herself). What was significantly new was the abrupt breaks in the music and in the use of materials (here a long piece of brown paper) to literally cut the movement of the dancers. Rather than the trance-like, automatic dance of the '50s, Hiérophanie was constructed to be deconstructed. An observer wrote that the impact of the dance "was troubling and fascinating ..." ${ }^{14}$ This is not the impact expected of the Automatiste who sought a return to a simpler time seeking to retrieve a universal myth, rather it is a tearing away at the myth, a deconstruction of the myth.

Similarly, another product of Sullivan's late 1970s practice centred on constructive/ deconstructive activity - the blocking and unblocking of doorways and windows. The record of these activities is photographic. It is the recording of the act which becomes the artifact. The exhibition of the photographs of the Fenêtres abandonnées, bloquées et debloquées (1978) was arranged in the gallery in such a way that the 
observer was forced to experience the event in one of two ways, either reconstructing the blocking by approaching from the end of the photo series which started with a photograph of the empty window, or by deconstructing the blockage by approaching from the opposite side of the gallery, where the series of photographs commenced with the image of a blocked window. In other words, the observer was choreographed through the exhibition. To what end? This presentation of photographs of the artist's personal experience becomes another event in its re-presentation. The use of the secondary medium forces the viewer to question what is being represented and to what degree the viewer is constructing the meaning/s available.

This layering of activity and meaning is also present in a later choreography Et la nuit ì la nuit (1981). Here again the critical response describes the enactment as a symbolic fertility rite, cites "La Danse et l'espoir" and comments on how "the archetypal elements which she has used before are found in a moving synthesis, profoundly human." ${ }^{15}$ Certainly the use of symbolic motifs underscores every move in this production. The use of the nude, pregnant woman who sedately carries in a basket at the end of the dance, and removes from it, half a dozen young rabbits is explicitly symbolic. While it has been observed that "[T]he dance finishes with this double symbol of fertility," it should not be inferred that the literal symbolism is meant to be the totality of the meaning. ${ }^{16}$ The choreographer herself states that $E t$ la nuit à la nuit was conceived in a state of semi-consciousness and built around several key images. ${ }^{17}$ While the choreographer may or may not have conceived the piece in such a state, the dance itself is performed according to prescribed choreographic directions. It is a predetermined enactment which regardless of the inspiration fulfils a specific intention. As such the Automatisme of its dancers is constrained if indeed it is possible. It is imperative to separate the 'automatiste impulse' of the author/choreographer from the directed movements of the dancers. In fact, Sullivan's choice of symbols and structuring of interactions would not support an unconscious expression but rather a very conscious examination of her world and the power relations of men and women. Nor is it possible to claim that this dance portrays the 'hope' of "La Danse et l'espoir." If anything, the dance explicitly challenges the 'natural' possibilities of "Le Grand Plein," the feminine archetype.

The three dance segments act out the symbolic relations between 
Man, symbolized as the River, and Woman, symbolized as the Mountain. The 'natural' progression of life is represented in vignettes describing the birth of man by woman, their consequent union, the eventual destruction of both, and the closing scene featuring the pregnant dancer. The dance appears to literally confirm the cycle of life. If, however, the dance is not interpreted in light of the 'hope' but in recognition of the shift in Sullivan's art practice (as exemplified above), then the dance could be understood as an allegory of desire. The use of multiple symbols is not necessarily only literal, and the literal and allegorical do not necessarily have to confirm each other. The rhetorical stance implicit in the anti-modern positions evidenced in Sullivan's work since 1970 can again be found in Et la nuit à la nuit. The title itself is dark and ambiguous - From the night to the night. There is no hope of breaking the cycle, doomed to repeat itself through birth, union and destruction; continuity may be ironic, satiric or pathetic, but hardly hopeful. The use of the nude woman reinforces her role as the vulnerable element in the equation. Her pride and self-confidence is misplaced in her fertility. Certainly, it is possible to read this piece as an anti-modern questioning of how we see ourselves and each other. This questioning of representation seems to be fundamental in Sullivan's choreography as well as in her visual art.

The use of symbols to construct a metaphor which is, in turn, deconstructed by the rhetorical stance of artist and viewer is evident in Sullivan's art practice of the 1980s. This brings us back to the question posed at the beginning of this essay - whether Sullivan's current art products, paintings or choreographic productions can be judged as continuous with her Automatiste stance of 1948.

The nearly pervasive tendency to interpret Sullivan's post-1970 work as somehow relating to her Automatiste writing "La Danse et l'espoir" and to her Danse dans la neige has created a methodological quagmire for the critics. On the one hand, they admire the consistency of her 'hope,' on the other they try to fit the artwork itself into that interpretation. Once performance is re-placed into Sullivan's oeuvre as an other expression, and not as a replication of prior concerns in a new mode, then it must be acknowledged that the fragmented nature of the work presents anything but a harmonious whole. Whether it is discontinuous dance or torn, unprimed, unmounted canvas which is the material, it appears that Sullivan can no longer be subsumed under the aesthetic conceptualization of Automatisme. Rather, the 
artist who refused to accept convention, whether aesthetic, social or political, in the Refus global, is still refusing the established categories. It is only by re-placing her performance art into her total oeuvre that such a reading becomes apparent.

\section{Notes}

1. Refus global, 1948, authorized translation by Ray Ellenwood, Total Refusal (Toronto: 1985), 37.

2. "La Danse et l'espoir" was read at an Automatiste evening at the Gauvreau apartment on February 16, 1948. C. Gosselin, "Sur Françoise Sullivan" in Françoise Sullivan Retrospective (Montreal: 1981), 21.

3. Cormier's article "L'oeuvre picturale est une expérience" was probably in progress before Sullivan's paper was read. It is evident that there was no one source for the expression of collective unconscious in this forum. While Cormier cited Freud in his essay, he referred to ideas which also reveal a Jungian conception of expressive energy of the unconscious, of the cosmos and of archetypes. See Elleriwood, 12, 93-100.

4. F. Sullivan, "La Danse et l'espoir" in Ellenwood, 106.

5. See M. Bousquet-Mongeau, C. Gosselin, and D. Moore, Françoise Sullivan Retrospective for the most extended discussion of Sullivan's oeuvre prior to 1981.

6. M. Saint-Pierre, "Françoise Sullivan - La Rhétorique du rêve, The Rhetoric of Dreams" Vanguard, Summer 1986, 38.

7. Ibid.

8. Ibid., 37.

9. Sullivan in Ellenwood, 115.

10. Interview with Claire Gravel "Françoise Sullivan - La Parole retrouvée" Vie des arts, Vol 32, 130 (March 88), 44-47. Gravel refers to Sullivan's comment on the impact of "Art After Philosophy" by J. Kosuth (1969) who refers to the "death of art."

11. Sullivan in an interview with Gilles Toupin, "La nostalgie de l'art" La Presse, Jan. 13, 1973, D-14.

12. Toupin, D-14.

13. D. Moore, "Françoise et l'espoir" in François Sullivan - Retrospective, 84.

14. Angèle Dagenais, "Françoise Sullivan: un retour à la choréographie" Le Devoir, 3 avr. 1979, D-7.

15. Ibid., 90 .

16. Iro Tembeck, "Danse à Quebec," Re-flex, 2, no. 1 (1982), 18.

17. F. Sullivan in publicity statements for Et la nuit à la nuit, Le Tritorium, Cegep de Vieux Montreal, 27 mars-1 avr., 1981. 